Lancet 1994;343:386-8.

4. Kim RJ, Iwai S, Markowitz SM, et al. Clinical and electrophysiological spectrum of idiopathic ventricular outflow tract arrhythmias. J Am Coll Cardiol 2007;49:2035-43.

5. Gupta AK, Shah CP, Maheshwari A, et al. Adenosine induced ventricular fibrillation in Wolff-Parkinson-White syndrome. Pacing Clin Electrophysiol 2002;25:477-80.

6. Exner DV, Muzyka T, Gillis AM. Proarrhythmia in patients with WolffParkinson-White syndrome after standard doses of intravenous adenosine. Ann Intern Med 1995;122:351-2.

7. Parham WA, Mehdirad AA, Biermann $\mathrm{KM}$, et al. Case report: adenosine induced ventricular fibrillation in a patient with stable ventricular tachycardia. J Interv Card Electrophysiol 2001;5:71-4.

8. Bayes de Luna A, Coumel P, Leclercq JF. Ambulatory sudden cardiac death: mechanisms of production of fatal arrhythmias on the basis of data from 157 cases. Am Heart J 1989;117:151-9.

9. Rankin AC, Oldroyd KG, Chong E, et al. Value and limitations of adenosine in the diagnosis and treatment of narrow and broad complex tachycardias. Br Heart J 1989;62:195-203.

10. Sharma AD, Klein GJ, Yee R. Intravenous adenosine triphosphate during wide QRS complex tachycardia: safety, therapeutic efficacy, and diagnostic utility. Am J Med 1990;88:337-43.

11. Hina K, Kusachi S, Takaishi A, et al. Effects of adenosine triphosphate on wide QRS tachycardia. Jpn Heart J 1996;37:463-70.

12. Innes JA. Review article: adenosine use in the emergency department. Emerg Med Australas 2008;20:209-15.

\section{A sentinel event for Ontario hospitals}

To the editor: In January of this year, the Huron Perth Healthcare Alliance of 4 Ontario hospitals (Stratford General Hospital, St. Mary's Memorial Hospital, Seaforth Community Hospital and Clinton Public Hospital) announced the reduction in hours of service of one of its emergency departments (EDs). The sole reason for the evening closure is a shortage of registered nurses (RNs). This will be the first time that a hospital ED in Ontario plans to reduce its operating hours for such a reason. It deserves considerable attention, since nursing unions, academic institutions and hospital administrations have been warning for many years that an RN shortage is reaching critical proportions in Ontario. As of Feb. 7, 2009, front-line health care delivery will be visibly and directly affected by this crisis.

The trends and statistics concerning nursing are widely available, and similar to many other professions and trades. They include an aging workforce; declining enrolment in training programs, paradoxically associated with an increased need; and, certainly in the long-term, simple demographics.

Small hospitals with minimal staffing and even less potential back up face the greatest challenge in RN staffing, because a shortage of 1 or 2 nurses can mean the difference between being able to offer a high standard of care, and being unable to offer any care at all.

Hospital administrations do their best to eliminate redundancy, maximize efficiency and optimize use of available human resources. But that does not address the root problem: there are not enough nurses entering the profession to replace those leaving it. It is as simple as that. With an aging population, there will soon be an even greater demand for nurses.

Before this crisis worsens, before more hospitals are obliged to reduce services, or close completely, action must be taken to correct this imbalance. As with the physician shortage, delays in implementing solutions will only mean fewer Ontarians have access to an acceptable quality of health care. Those with a voice at all levels of health care delivery need to make government authorities understand the scale of the problem, and lobby for solutions at a system level. Provincial ministries of economic development, education, health and long-term care, health promotion, labour, training, and colleges and universities need to become part of the solution. A coordinated action plan for encouraging people to enter the nursing profession and seek out careers where they are most needed, for recruiting qualified RNs from other locations around the world and for making the commitment to see such a plan succeed is as necessary a part of health care reform in Ontario as wait time strategies and patient safety indicators. It's time the public became aware of this threat to health care and demand solutions from those who serve the public good.

Perhaps the overnight closure of the ED at the Seaforth Community Hospital can serve as a sentinel event, the "canary in the coal mine" for this crisis, and prompt the kind of commitment to change that health care in Ontario really needs.

\section{Jason Datema, MD}

Site Chief, Seaforth Community

Hospital, Seaforth, Ont.

\section{Advocate or abdicate: the responsible choice for today's emergency medicine resident}

To the editor: I think it can be safely argued that many of the problems that now beset emergency medicine (e.g., crowding, insufficient human resources and service disruptions) are, in part, a result of a lack of advocacy by our specialty during the 1990s when these problems first reared their ugly heads. This is not to lay blame on those who sat on the various executives at that time (I was there until 1994!). It is simply a statement of fact that our specialty and our association lacked organizational maturity at that time and had too many other diversionary issues.

Clearly, if the sins of the fathers are not to be repeated, then it is important that our specialty embrace 
the importance of advocacy in improving system development, patient care and the quality of our working environment.

Therefore, I was most gratified to read the January 2009 issue of CJEM and, more particularly, the residents' corner article, ${ }^{1}$ in which the author promotes that advocacy be engrained into the role of every emergency physician. I obviously agree and believe that current training programs could do more to provide residents with the necessary tools to be effective advocates for our specialty and our concerns. ${ }^{2,3}$

Just as residents are now taught the fundamentals of good clinical research and are expected to complete a research project during their training, so too should they be provided with the opportunity to get involved in an advocacy initiative.

Yes, research is important, but, at the end of the day, somebody has to be available to synthesize and promote the central messages of that body of research to health policy experts, health ministers, opposition health critics and the press. I have never yet met a health minister who has ever read CJEM or the Annals of Emergency Medicine.

Since forming the Canadian Associa- tion of Emergency Physicians (CAEP) Public Affairs Committee a few short years ago, I have come to realize that it is a bit of a thankless job. Hours are spent monitoring the press reports on emergency services; responding, where appropriate, with letters to the editor or with media interviews; attending countless meetings with government officials, politicians and allied health groups; and lecturing at every possible opportunity on the need for direct advocacy, only to read in the latest membership survey that we have not been doing enough.

Still, there is tremendous personal satisfaction in knowing that we have indeed made a quiet difference. For example, despite the public statements and political posturing by various provincial governments in the past several years, I can assure you that they privately confess to knowing full well that overcrowding will not be solved until there has been a restitution of adequate bed capacity. CAEP's Stop the Waiting campaign has therefore, in my estimation, played a hugely successful role in changing the language and the paradigm of overcrowding. Now, if only we could control the health care budget.
Residents can incorporate advocacy into their residency experience and realize early benefits in their career development by playing an active role in shaping meaningful and lasting public health policy. ${ }^{4,5}$ So, rather than waiting until residency is over, I would encourage residents to join their more senior colleagues on CAEP's Public Affairs Committee in our efforts to promote a better emergency health system. Please feel free to contact me directly at drummond@ripnet.com.

\section{Alan Drummond, MDCM \\ Perth, Ont.}

\section{References}

1. Lai J. Health advocacy in emergency medicine: a resident's perspective. CJEM 2009;11:99-100.

2. Bandiera G. Emergency medicine health advocacy: foundations for training and practice. CJEM 2003;5:336-42.

3. Hurley KF. Advocacy and activism in emergency medicine. CJEM 2007;9: 282-5.

4. Ovens H, Morrison H, Drummond A, et al. The case for mandatory reporting of gunshot wounds in the emergency department. Toronto $(\mathrm{ON})$ : The Ontario Medical Association; 2003. Available: www.oma.org/pcomm/OMR/nov/03 gunshot.htm (accessed 2009 Jan 27).

5. Snider CE, Ovens H, Drummond A, et al. CAEP Position Statement on Gun Control. CJEM 2009;11:64-72.

\section{Erratum}

In the January 2009 issue, there was a typing error in the abstract for the article entitled "Validity of the Canadian Paediatric Triage and Acuity Scale in a tertiary care hospital." The first sentence of the conclusion should read, "This computerized version of PaedCTAS demonstrates a strong association with admission to hospital, admission to PICU and LOS in the ED."

\section{Reference}

1. Gravel J, Manzano S, Arsenault, M. Validity of the Canadian Paediatric Triage and Acuity Scale in a tertiary care hospital. CJEM 2009;11:23-8. 